\title{
Poetry in Medicine
}

\author{
Naaz Jahan Shaikh ${ }^{1}$
}

Received: 12 September 2017 / Accepted: 17 October 2017 /Published online: 24 October 2017

(C) Association of Surgeons of India 2017

\begin{abstract}
We are all stressed out to read and understand our medical practice which is so vast and seems monotonous. Amidst so much tension, we can still enjoy our profession if we can narrate the sequence in a different style. Poetry is one way of such expression.

Poetry is a combination of knowledge and feeling. Just as we have all read Zachary Cope's Surgery in Verse which correlates the disease with its signs in a different way that is poetry, I have tried to use poetry in my medical practice, too. We can understand as well as express better. The whole topic seems so easy once it comes in the form of poetry.

Writing in a poetic form requires a thorough knowledge of the subject. Added to this are empathy and sympathy. It needs a deep sense of understanding to feel what the sufferer would feel. Imagination can take us to any part of the world and beyond however minute the structure imagined may be. This is an attempt to present poetry in medical, both while learning and during practice.
\end{abstract}

Naaz Jahan Shaikh

drnaazciti@yahoo.co.in

1 Citi Hospital, Hosapete, Bellary District, Karnataka, India

\section{When the Bag is in Trouble...}

That pear shaped bag...

Lying humbly under the liver crag

Performing till date the duty allotted

Until the time its contents got tainted.

Precipitation of the sludge

Stones at times resembling fudge

Silent often... but sometimes yell

Their untold story they seem to tell.

The undefiable 'f' sequence

Now and then have given credence

When Murphy's sign gives a clue

It is time now to inform the crew.

The situation is grim with a triad of charcot

Worsened further with a pentad of Reynold

Intervention is needed to clear the yellow...

Needed at times is the help of an expert fellow.

Acoustics and the magnets will guide you

Knowledge of the anatomy will always take you through

Hug me says the gall bladder

Lest you put the pivotal trunk in danger!!

COSIC... will ease the situation

Doing less is better than a stupid temptation!

Ignorance of the miss is worse than committing

Safe conversion is always worth attempting!! 